\title{
Adaptive Support Ventilation versus Conventional Ventilation during Hypoxemic Respiratory Failure: A Meta-analysis of Randomized Controlled Trials
}

\section{Wei Zhang ( $\square$ zhangwei_hxicu@163.com )}

Affiliated Hospital of Zunyi Medical College https://orcid.org/0000-0002-8706-6082

Xiaoli Liu

Affiliated Hospital of Zunyi Medical College

\section{Can Jin}

Affiliated Hospital of Zunyi Medical College

\section{Longju Zhang}

The First People's Hospital of Zunyi City

\section{Zong'an Liang}

Sichuan University West China Hospital

\section{Research article}

Keywords: pulmonary infection, critically ill patients, adaptive support ventilation, hypoxemic respiratory failure

Posted Date: March 10th, 2020

DOI: https://doi.org/10.21203/rs.3.rs-16457/v1

License: (9) (i) This work is licensed under a Creative Commons Attribution 4.0 International License. Read Full License 


\section{Abstract}

Background The purpose of the study is to examine whether the adaptive support ventilation (ASV) mode compared with conventional ventilation reduces the duration of mechanical ventilation (MV) in patients with acute respiratory failure.

Methods We searched PubMed, the Cochrane Library Central Register of Controlled Trials, EMBASE and Web of Science databases from inception through July 27,2019 . We considered all the randomized controlled studies (RCTs) that examined the efficacy of ASV in comparison with conventional ventilation in mechanically ventilated adults. The primary outcomes were (1) the length of MV, (2) weaning duration and (3) length of stay (LOS) in ICU.

Results We included three RCTs for the analysis enrolling a total of 374 patients. Patients treated with ASV had a lower weaning

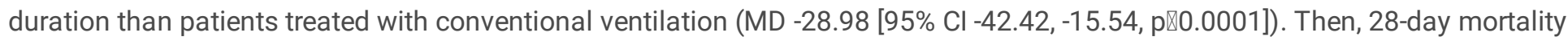
was not different between the two groups (OR $0.95[95 \% \mathrm{Cl} 0.6,1.52, \mathrm{p}=0.83 ; \mathrm{I} 2=0 \%, \mathrm{p}=0.96])$. The incidence of ventilatorassociated pneumonia and sedation level was not included into the quantitative analysis.

Conclusions The study showed that a lower number of duration of $\mathrm{MV}$ and a shorter number of weaning duration in acute hypoxemic respiratory failure patients treated with ASV than conventional ventilation. Keywords: pulmonary infection; critically ill patients; adaptive support ventilation; hypoxemic respiratory failure Background Acute hypoxemic respiratory failure is a severe disorder of the respiratory system to maintain oxygenation or eliminate carbon dioxide (CO2), leading to a series of metabolic disorders and physiological dysfunction. Mechanical ventilation (MV) serve as a lifesaving therapy is widely employed in intensive care units (ICU) for treating clinical symptoms related to critically illness.[1,2] Employment of mechanical ventilation in patients could help effectively to replace, control and change spontaneous breathing, reduce or eliminate respiratory muscle oxygen consumption, increasing ventilation and improving ventilation[3], removing the residual mucous in airway.[4] The choice of ventilation mode is such a very important issue in ICU that clinicians capable to choose the ventilation mode and adapt the ventilator controls according to the patient's respiratory mechanics.

\section{Background}

Acute hypoxemic respiratory failure is a severe disorder of the respiratory system to maintain oxygenation or eliminate carbon dioxide $\left(\mathrm{CO}_{2}\right)$, leading to a series of metabolic disorders and physiological dysfunction. Mechanical ventilation (MV) serve as a lifesaving therapy is widely employed in intensive care units (ICU) for treating clinical symptoms related to critically illness.[1,2] Employment of mechanical ventilation in patients could help effectively to replace, control and change spontaneous breathing, reduce or eliminate respiratory muscle oxygen consumption, increasing ventilation and improving ventilation[3], removing the residual mucous in airway.[4] The choice of ventilation mode is such a very important issue in ICU that clinicians capable to choose the ventilation mode and adapt the ventilator controls according to the patient's respiratory mechanics.

Adaptive support ventilation (ASV) is a closed-loop mode, as a newer protective ventilation mode, which can act both as pressure-control synchronized intermittent mandatory ventilation or pressure support ventilation. The first clinical application was described in the literature in 1994 by Laubscher and colleagues[5,6] that characterized with assist-control, pressure-targeted, time-cycled mode of ventilation. It is considered to be the first available ventilator system that uses an "optimal" targeting schema[7]. When using ASV, the preset parameters are far less than other modes. It includes three parameters: (1) minute ventilation percentage (MinVol\%). When the preset MinVol\% is $100 \%$, the minute ventilation provided by the ventilator is $0.1 \mathrm{l} / \mathrm{kg}$ (adult) and $0.2 \mathrm{l} / \mathrm{kg}$ (child); (2) airway pressure alarm high limit; (3) patient ideal weight. Theoretically, this optimal ventilator work may ensure adequate MinVol\% with least possible airway pressure[8] which, in turn, reducing the risk of ventilator-associated lung injury. The majority of benefits regarding the ASV used in weaning postoperative patients with shortening weaning time, reducing the need for arterial blood gas (ABG) analyses, and fewer number of manual ventilator setting changes[9-11]. In a clinical study of ASV compared with synchronized intermittent mandatory ventilation (SIMV) of chronic obstructive pulmonary disease (COPD) patients showed that $\mathrm{PaO}_{2}, \mathrm{pH}$, and $\mathrm{SaO}_{2}$ values were remarkably increased, peak airway pressure (PIP) value was significantly decreased, showed that lowing pressure of ASV could reduce the occurrence of ventilator-associated lung injury (VALI), and improve the respiratory function and ventilation volume and decrease the burden of respiratory muscles and improve clinical outcomes[12]. In experiments related to respiratory mechanics showed that decreased inspiratory load and improved 
patient-ventilator interactions benefit from the central respiratory drive and sternocleidomastoid activity were obviously decrease[13]. A physiological study of respiratory failure, ASV was found superior in hemodynamics, ventilatory and gas exchange parameters[14].

ASV was well known as safety, comfort, and liberation, which can minimize the work of breathing and improve the outcomes in hypoxemic respiratory failure (HRA), and have largely fallen under this "less-is-more" mechanical ventilation strategy, then commonly used in invasive mechanical ventilation.

However, Agarwal et al [15]showed that acute respiratory distress syndrome (ARDS) patients with ASV and volume-cycled ventilation (VCV) have no significant difference in duration of MV, intensive care unit and hospital stay, the mortality and the number of arterial blood gas also have no statistically significant between the two group, when respiratory system compliance failure or mechanical-ventilator asynchrony may amplify VALI.[16]

Whether the ASV mode have a positive impact on passive ventilation patients compared to conventional ventilation strategies remains unclear. Herein, the aim of this meta-analysis is to assess the outcomes of duration of MV, ICU length of stay, successfully extubated rate, the mortality day of 28 and weaning duration in ASV versus conventional ventilation in critically ill adults with hypoxemic respiratory failure.

\section{Methods}

A meta-analysis of RCTs was conducted to compare the length of MV, ICU length of stay (LOS), and weaning period in ASV outcomes of acute respiratory failure. All the data of the study were included from published RCTs, we complied with the PRISM (Preferred Reporting Items for Systematic Reviews and Meta-analyses) [17]statement for reporting this study.

\section{Data sources and search strategy}

We performed an electronic databases search of PubMed, Cochrane Central Register of Controlled Trials, EMBASE and Web of Science database from their inception to July 27, 2019 for eligible studies, we combined the terms 'adaptive support ventilation ;' 'closed-loop control ventilation,' 'ASV,' 'anoxemia,' 'hypoxemia,' 'hypoxemic respiratory failure,' 'oxygen deficiency' 'COPD,' 'chronic obstructive pulmonary disease', 'ARF,' and 'acute respiratory failure' were used. The searches were limited to English publications as well as RCTs. Results were then filtered for adult human's studies. Furthermore, we also trying to contact the authors to get the original studies to obtain additional information.

\section{Eligibility criteria}

We included randomized controlled trials (RCTs) that examined the efficacy of ASV mode in comparison with conventional ventilation in adults (aged $\geq 18$ years, who were diagnosed with acute hypoxemic respiratory failure (PaO2/FiO2 $₫ 300 \mathrm{mmHg})$. All these patients were hospitalized in ICU in respiratory department. All patients had been found to have respiratory failure, which required mechanical ventilation. We excluded observational studies, case series and case reports, studies published in abstracts, literature reviews, editorials, as well as randomized control group studies that applied ASV mode no clinical prognostic related results.

\section{Data extraction and bias assessment}

The retrieved results were combined and removed duplicated records. Two investigators (Xiaoli Liu and Wei Zhang) independently abstracted titles and abstracts and screed the full-text of the reports from our search. Details of the adaptive support ventilation mode used and relevant outcomes were recorded. When data about an outcome of the study were missing, the authors were contacted to clarify abstracted data and obtain patient-relevant data to ensure accuracy in the review. All disagreements at any step of the process were resolved by discussion or by the opinion of a third investigator (Zongan Liang) if necessary. 
The same investigators also independently assessed the risk of bias using Cochrane risk bias tool[18] (http://ims.cochrane.org/revman). Two investigators (Xiaoli Liu and Wei Zhang) subjectively reviewed all studies and assigned a value of 'high,' 'low, or 'unclear' in the following: (1) selection bias (was there randomization sequence? Was allocation concealment satisfactory?) (2) performance bias (was there adopted uniform and standardized treatment plan?) (was there blinding participants, personnel, and outcome assessment?) (3) measurement bias (was there adopt standardized measurement methods?) (4) attrition bias (were incomplete outcome data Fully evaluated and processed?) (5) reporting bias (was there selective outcome reporting?) (6) other biases (was the study avoid other problems that could put it at a high risk of bias?).

\section{Collection and Analysis of Data}

The RCTs included in this study, duration of mechanical ventilation, ICU LOS and weaning period in acute respiratory failure applied in ASV was the primary outcome. We abstracted and collected data, including the first author, published year, participants' baseline characteristics, the type of patients, $\mathrm{PaO2} / \mathrm{FiO} 2$ at baseline ( $\mathrm{mmHg}$ ), MV before randomization (h), ASV initial setting, intervention, and outcome.

\section{Outcomes}

Our Primary outcomes were: (1) duration of mechanical ventilation, defined as the time from intubation until last successful extubation; (2) ICU length of stay; (3) weaning duration, defined as the time from randomization to spontaneous breathing with or without a tracheotomy; the secondary outcomes included (1) 28-day mortality; (2) weaning success rates.

\section{Statistical analysis}

We used RevMan version 5.3 software for all data and statistical analyses. For dichotomous outcomes were calculated using the Mantel-Haenszel $(\mathrm{MH})$ method and were expressed with odds ratios (OR), for continuous outcomes, using random-effects model and were calculated by weighted mean difference (WMD) and presented the results with associated $95 \%$ confidence intervals (Cls) for the included studies reported continuous outcomes in medians and interquartile ranges, we estimated the means and standard deviations (SD) using a method proposed by Wan et al.[19] Heterogeneity was assessed with the $R$ statistic and defined as greater than $50 \%$ being considered substantial,[20] the random-effects model was used for all analyses. Potential publication bias was not assessed because of the number of included studies of less than 10. [18] A $p$ value of less than 0.05 was considered statistically significant.

\section{Results}

\section{Study identification and selection}

Using the outlined search strategy, we identified 742 citations. Fig 1 shows the study search strategy according to PRISMA guidelines[17]. After removal of duplicates, a total of 653 citations were screed of titles and abstracts, and assessed the full text of twenty articles. Of these, we considered three RCTs [15,21,22], 374 patients, 186 ventilated with ASV and 188 with conventional ventilation mode) met criteria for inclusion (Fig.1). Table 1 describes the main characteristics of the selected studies. The studies were published from 2011 to 2014. All studies were the single centered RCTs. The sample size per RCT from 48 to 229 . Three studies enrolled patients with invasive mechanical ventilation (MV) of critically illness, including acute respiratory failure disease (ARDS, COPD, CAP, sepsis, cardiac et al), arterial oxygen tension $\left(\mathrm{PaO}_{2} / \mathrm{FiO}_{2}<300 \mathrm{mmHg}\right.$ and need invasive $\mathrm{MV}$ support. One study specifically enrolled only patients with COPD who need invasive mechanical ventilation[21], another study enrolled mainly patients with COPD,[23] including overall 374 patients(COPD patients accounted for $61.2 \%$ of the total population considered), COPD patients with a confirmed diagnosis according to the Global Initiative for Chronic Obstructive Lung Disease (GOLD) criteria were included in the study[23] the third study enrolled only patients with ARDS (12.8\% of the total population considered).[22] All patients requiring invasive mechanical ventilation were eligible for $\mathrm{PaO}_{2} / \mathrm{FiO}_{2}<300 \mathrm{mmHg}$. At the initial ASV setting, three studies measured a Ppeak $₫ 45 \mathrm{cmH} 20$

MinVol \% 100\% (0.1/kg PBW( predicted body weight)), positive end expiratory pressure (PEEP) $3-5 \mathrm{cmH} 20, \mathrm{FiO} 2 \leq 40 \%$ and use this data to set tidal volume (VT) and respiratory frequency (fR). 
About outcomes, all studies [15,21,22]reported duration of MV, ICU LOS, two studies reported weaning duration, weaning success rate and 28-day mortality.[21,22]

\section{Primary outcomes}

Three RCTs reported primary outcomes as duration of MV, the overall MD between ASV and conventional ventilation was (MD $-33.60[95 \% \mathrm{Cl}-54.21,-12.99, p=0.001 ; R=13 \%, p=0.32]$ ), (Fig 2-1) the aggregate results of these studies suggested that ASV was associated with a significant improvement in duration of MV and ICU LOS (MD-1.17 [95\%Cl $-2.36,0.03, p=0.06 ; P=0 \%, p=0.89])$ (Fig 2-2) ASV compared with conventional ventilation was not statistic significant. From two studies[21,22] we concluded that between the two groups the weaning duration was different (MD -28.98 [95\% Cl -42.42, -15.54, $p \bigotimes 0.0001 ; R=61 \%, p=0.11])($ Fig 2$3)$, shows that ASV as a new ventilation mode is suitable used in weaning period.

\section{Secondary outcomes}

Two studies[21,22] did not show any differences in weaning successful rate (OR $1.36[95 \% \mathrm{Cl} 0.87,2.12, p=0.18 ; P=0 \%, p=0.64])$ (Fig 2-4). Then, 28-day mortality was not different between the two groups (OR $0.95[95 \% \mathrm{Cl} 0.6,1.52, p=0.83 ; P=0 \%, p=0.96])(\mathrm{Fig}$ 2-5). This may be an inaccurate results for the small scale of literature pooled.

\section{Risk of Bias}

Fig 3 shows an evaluation of the risk of bias. All of the trials were randomized, one trials met double-blind[22], two of the studies[15,22] described an explicit generation process of a random sequence and the methods that were applied to allocation concealment. As the studies included were less than ten, a publication bias analysis was not performed. All of the studies were estimated to have a low risk of bias.

\section{Discussion}

This study was the first meta-analysis investigating the clinical effects of ASV on critically ill adult patients affected by acute HRA. Our results demonstrated that ASV as a ventilation mode has a positive improvement effect on shortening mechanical ventilation time and expedited weaning. Therefore, for patients with acute respiratory failure may lead to the reduction of complications and costs, ASV could be a viable alternative to MV.

ARF could result in a series of physiological functions and metabolic disorders in the body. The onset of illness develops rapidly, which required emergency treatment, or admitted to the intensive care unit (ICU). MV is the main treatment for ARF, which can alleviate the patient's conditions. Researches on clinical ASV have been approaching more than 20 years, while this technique can facilitate many scenes. Currently, ASV as a mode of MV has become one of the hot spots of severe rescue treatment, applying in the acute and weaning phases of ventilation. The computerized control system is used to comprehensively monitor the patient's immediate conditions, and the breathing parameters are automatically set according to the patient's ventilation needs and respiratory capacity. And adjustment, which in turning converts complete supports ventilation into partial support ventilation. ASV also replaces other ventilation modes designed solely for a specific phase of MV, during the initiation, maintenance or weaning from MV.[24] It cannot only provide the most benefit in resource limited environments[25, 26] saving cost and according to change the delivered pattern (VT and $\mathrm{FR}$ ) based on the underlying condition, but minimize the incidence of VALI,[27-29] successfully fast weaning and reduce the risk of reintubated.[30,31] Studies have indicated a reduces in respiratory load and establish a state of hyperventilation to provide a safe and efficient ventilation mode for patients [32].

At the same time, it is also able to guide the patient to prepare for the weaning, and assist and retain the patient's spontaneous breathing function on the basis of ensuring the patient's basic oxygen supply requirements. [33] However, these studies did not provide adequate data or sufficient clinical evidence to support the beneficial effects of ASV ventilator mode on these relevant findings.

Our results suggested that the ventilation mode of ASV shortened ICU LOS in three studies [15, 21,22]. This results indicates that ASV can have a clinical effect on HRF patients, our meta-analysis also found that patients treated with ASV had a statistically 
significant higher value of weaning duration than patients on conventional ventilation, the difference was clinically significant

(MD -28.98; 95\% Cl -42.42, -15.54, p $ه 0.0001$ ). This result shows that the ASV mode is a good alternative to the ventilator weaning phase, consistent with the literature report.[26]

The mechanisms of ASV responsible for its beneficial effects that differ from other mode of ventilation have yet to be elucidated. Several factors may be responsible for the beneficial effects seen in the patients undergoing ASV ventilation aside from conventional ventilation.

There are several theoretical advantages of ASV. Extubation readiness was recognized earlier with ASV,[26] since ASV can help recognize extubation readiness with fewer manipulations.[34] Additionally, the airway pressure is always in a safe range, through a lung protection strategy, and solves the relevant mechanical complications such as apnea, volutrauma, barotrauma and/or dead space ventilation.[35] Finally, the patient is always in the best breathing state, may also decrease inspiratory load, improve patient-ventilator interaction,[36] and decrease the need to adjust ventilator settings,[37] avoiding the rapid breathing or suffocation.

Several limitation are identified in our study. Firstly, included trials significantly varied in terms of disease, intervention protocol, duration, patient population, and study quality, which limit the conclusive extent for the overall effectiveness of ASV on ICU LOS, and weaning duration analysis in patients with HRF. Secondly, our analysis is based on only three RCTs, and only a maximum of only three studies was available for the main outcomes. In addition, studies ranged from 2011 to 2014 hence it encompasses a narrow time frame which may affect the results as over the years better are available? Moreover, these studies have a wide variation in type of disease, there are included in different disease variety may relevant to minor differences in disease pathogenesis and different rescue measures and ventilator parameter settings. The smaller sample size of trials may have significantly overestimated the treatment effect. Finally, several missing and unpublished data may lead to bias.

\section{Conclusions}

In the study we found that ASV effectively improves the rate of successful extubation in patients with ARF compared with conventional therapy.

\section{Abbreviations}

ICU intensive care unit

CV conventional ventilation

ARDS acute respiratory distress syndrome

COPD chronic obstructive pulmonary disease

CAP community-acquired pneumonia

$\mathrm{CO}_{2}$ carbon dioxide

HRA hypoxemic respiratory failure

ASV adaptive support ventilation

ARF acute respiratory failure

RCT randomized controlled trial

MV mechanical ventilation

ABG arterial blood gas

Page 6/14 
SIMV synchronized intermittent mandatory ventilation

PIP peak airway pressure

$\mathrm{PaO}_{2}$ partial pressure of oxygen

$\mathrm{pH}$ hydrogen ion concentration

$\mathrm{SaO}_{2}$ arterial oxygen saturation

VCV volume-cycled ventilation

LOS length of stay

PRISM preferred reporting items for systematic reviews and meta-analyses

VALI ventilator-associated lung injury

$\mathrm{PaO2} / \mathrm{FiO2}$ arterial oxygen tension/ inspired oxygen fraction

Ol oxygenation index

MH Mantel-Haenszel

OR odds ratios

WMD weighted mean difference

$\mathrm{Cl}$ confidence interval

SD standard deviations

GOLD Global Initiative for Chronic Obstructive Lung Disease

PEEP positive end expiratory pressure

PBW predicted body weight

Ppeak peak pressure

VT tidal volume

$f R$ respiratory frequency

\section{Declarations}

\section{Ethics approval and consent to participate}

This is a meta-analysis article, so the ethics approval and consent to participate could not be required.

\section{Consent for publication}

All authors have read and approved the manuscript version, and agree to submit for consideration for publication in the journal.

\section{Availability of data and material}

The data and material are available in this paper. 


\section{Competing interests}

There are no ethical/legal conflicts involved in the article.

\section{Funding}

This study was funded by the Zunyi Medical College 2017 Academic New Seedling Cultivation and Innovative Exploration Fund (Qian Ke He Talents Platform $₫ 2017 \rrbracket 5733-019$ ) and Science and Technology Support Plan of Guizhou Province in 2019 (Qian Ke He Support $\ 2019 \llbracket 2834$ ) of Professor Wei Zhang.

\section{Authors' contributions}

Wei Zhang and Zong'an Liang had full access to all of the data in the present case and accept responsibility for data management and the accuracy of data for analyses. Study concept and design: Xiaoli Liu and Wei Zhang. Acquisition and interpretation of data: Can Jin, Longju Zhang, and Wei Zhang. Drafting of the manuscript: Xiaoli Liu and Wei Zhang. Critical revision of the manuscript for important intellectual content: Wei Zhang and Zong'an Liang. Administrative, technical, or material support: Wei Zhang and Zong'an Liang. Study supervision: Wei Zhang and Zong'an Liang. All authors agreed to submission of the final version of this manuscript. Wei Zhang and Zong'an Liang are the study guarantor.

\section{Acknowledgement}

We would like to thank the authors of the original studies included in this meta-analysis, and the useful comments and criticism of the reviewers and the editorial staff.

\section{References}

[1] Metnitz PG, Metnitz B, Moreno RP, et al; SAPS 3 Investigators: Epidemiology of mechanical ventilation: Analysis of the SAPS 3 database. Intensive Care Med 2009; 35:816-825.

[2] Esteban A, Frutos-Vivar F, Muriel A, et al: Evolution of mortality over time in patients receiving mechanical ventilation. Am J Respir Crit Care Med 2013; 188:220-230.

[3] Tassaux D, Dalmas E, Gratadour P et al. Patient-ventilator interactions during partial ventilatory support: A preliminary study comparing the effects of adaptive support ventilation with synchronized intermittent mandatory ventilation plus inspiratory pressure support. Critical Care Medicine. 2002,30(4):801-807.

[4] Terblanche M, Kruger P, di Gangi S et al. Risk factors for acute organ failure in intensive care unit patients who receive respiratory support in the absence of non-respiratory organ failure: An international prospective cohort study. Critical Care, 2012 16(2):R61.doi:10.1186/cc11306.

[5] Laubscher TP, Frutiger A, Fanconi S et al. Automatic selection of tidal volume, respiratory frequency and minute ventilation in intubated ICU patients as start up procedure for closed-loop controlled ventilation. Int. J. Clin. Monit. Comput. 1994; 11: 19-30.

[6] Laubscher TP, Heinrichs W, Weiler $\mathrm{N}$ et al. An adaptive lung ventilation controller. IEEE Trans. Biomed Eng. 1994; 41: 51-9.

[7] Mireles-Cabodevila E, Diaz-Guzman E, Heresi GA, Chatburn RL. Alternative modes of mechanical ventilation: A review for the hospitalist. Cleve Clin J Med. 2009;76:417-30.

[8]Campbell RS, Branson RD, Johannigman JA. Adaptive support ventilation. Respir. Care Clin. N. Am. 2001; 7: 425-40.

[9] Sulzer CF, Chioléro R, Chassot PG, Mueller XM, Revelly JP. Adaptive support ventilation (ASV) for fast tracheal extubation after cardiac surgery. A randomized controlled study. Anesthesiology 2001;95:1339-45. 
[10] Gruber PC, Gomersall CD, Leung P et al. Randomized controlled trial comparing adaptive-support ventilation with pressure regulated volume-controlled ventilation with automode in weaning patients after cardiac surgery. Anesthesiology 2008; 109:817.

[11] Dongelmans DA, Veelo DP, Paulus F et al. Weaning automation with adaptive support ventilation: a randomized controlled trial in cardiothoracic surgery patients. Anesth. Analg. 2009; 108:565-71.

[12] Ling Han, Yingxiao Wang, Yonghua Gan et al. Effects of Adaptive Support Ventilation and Synchronized Intermittent Mandatory Ventilation on Peripheral Circulation and Blood Gas Markers of COPD Patients with Respiratory Failure. Cell Biochem Biophys,2014,70:481-484.

[13] Tassaux D, Dalmas E, Gratadour P et al. Patient-ventilator interactions during partial ventilatory support: a preliminary study comparing the effects of adaptive support ventilation with synchronized intermittent mandatory ventilation plus inspiratory pressure support. Crit Care Med. 2002,30(4):801-7. doi: 10.1097/00003246- 200204000 -00014.

[14] lotti GA, Polito A, Belliato M et al. Adaptive support ventilation versus conventional ventilation for total ventilatory support in acute respiratory failure. Intensive Care Med. 2010; 36:1371-9.

[15] Agarwal R, Srinivasan A, Ashutosh $\mathrm{N}$ et al. Adaptive support ventilation for complete ventilatory support in acute respiratory distress syndrome: A pilot, randomized controlled trial. Respirology 2013;18:1108-1115.doi: 10.1111/ resp. 12126

[16] Slutsky AS. Neuromuscular blocking agents in ARDS. N. Engl. J. Med. 2010; 363: 1176-80.

[17] Liberati A, Altman DG, Tetzlaff J, et al. The PRISMA statement for reporting systematic reviews and metaanalyses of studies that evaluate health care interventions: explanation and elaboration. Ann Intern Med.2009;151:W65-94.

[18] Higgins J, Green S. Cochrane handbook for systematic reviews of interventions. Chichester : Wiley, 2008.

[19] Wan X, Wang W, Liu J, et al. Estimating the sample mean and standard deviation from the sample size, median, range and/or interquartile range. BMC Med Res Methodol 2014; 14.

[20] Higgins JP, Thompson SG. Quantifying heterogeneity in a meta-analysis. Stat Med 2002;21:1539-58.

[21] Kirakli C, Ozdemir I, Ucar ZZ et al. Adaptive support ventilation for faster weaning in COPD: a randomised controlled Trial. Eur Respir J 2011; 38: 774-780 DOI: 10.1183/09031936.00081510.

[22] Kirakli C, Naz I, Ediboglu O, et. al. A randomized controlled trial comparing the ventilation duration between Adaptive Support Ventilation and Pressure Assist/Control Ventilation in medical ICU patients. Downloaded From:

http://journal.publications.chestnet.org/ by a SUNY Downstate Medical Center User on 03/29/2015.

[23] Asia-Pacific COPD Roundtable Group. Global Initiative for Chronic Obstructive Lung Disease strategy for the diagnosis, management and prevention of chronic obstructive pulmonary disease: an Asia-Pacific perspective. Respirology 2005; 10 : 9-17.

[24] Jaime Fernández, Dayra Miguelena, Hernando Mulett et al. Adaptive support ventilation: State of the art review. Indian J Crit Care Med. 2013 Jan-Feb; 17(1): 16-22.

[25] Embriaco N, Papazian L, Kentish-Barnes N, Pochard F, Azoulay E. Burnout syndrome among critical care healthcare workers. Curr Opin Crit Care 2007;13(5):482-488.

[26] Chen CW, Wu CP, Dai YL, Perng WC, Chian CF, Su WL, Huang YC. Effects of implementing adaptive support ventilation in a medical intensive care unit. Respir Care 2011;56(7):976-983.

[27] Belliato M, Palo A, Pasero D, lotti GA, Mojoli F, Braschi A. Evaluation of adaptive support ventilation in paralysed patients and in a physical lung model. Int J Artif Organs. 2004;27:709-16.

Page $9 / 14$ 
[28] Tassaux D, Dalmas E, Gratadour P, Jolliet P. Patient-ventilator interactions during partial ventilatory support: A preliminary study comparing the effects of adaptive support ventilation with synchronized intermittent mandatory ventilation plus inspiratory pressure support. Crit Care Med. 2002;30:801-7.

[29] Sulemanji D, Marchese A, Garbarini P, Wysocki M, Kacmarek RM. Adaptive support ventilation: An appropriate mechanical ventilation strategy for acute respiratory distress syndrome? Anesthesiology. 2009;111:863-70.

[30] Sulzer CF, Chiolero R, Chassot PG et al. Adaptive support ventilation for fast tracheal extubation after cardiac surgery: a randomized controlled study. Anesthesiology 2001; 95: 1339-45.

[31] Cassina T, Chiolero R, Mauri R et al. Clinical experience with adaptive support ventilation for fast-track cardiac surgery. J. Cardiothorac. Vasc. Anesth. 2003; 17: 571-5.

[32] Arnal JM, Wysocki M, Novotni D, et al. Safety and efficacy of a fully closed-loop control ventilation (IntelliVent-ASV $\AA^{8}$ ) in sedated ICU patients with acute respiratory failure: a prospective randomized crossover study[J].Intensive Care Medicine, 2012,38 (5):781-787.

[33] Taguchi S, Imai Y, Sasaki M, et al. Coronary artery bypass graft (CABG) in a patient with chronic obstructive pulmonary disease (COPD) who showed difficulty in respiratory control[J].Masui, 2012, 61(4):411-413.

[34] Petter AH, Chiolero RL, Cassina T, Chassot PG, Muller XM, Revelly JP. Automatic "respirator/weaning" with adaptive support ventilation: the effect on duration of endotracheal intubation and patient management. Anesth Analg 2003;97(6):1743-1750.

[35] Campbell RS, Branson RD, Johannigman JA. Adaptive support ventilation. Respir Care Clin N Am. 2001;7:425-40.

[36] Veelo DP, Dongelmans DA, Binnekade JM, Paulus F, Schultz MJ. Adaptive support ventilation: A translational study evaluating the size of delivered tidal volumes. Int J Artif Organs. 2010;33:302-9.

[37] Laubscher TP, Frutiger A, Fanconi S, Jutzi H, Brunner JX. Automatic selection of tidal volume, respiratory frequency and minute ventilation in intubated ICU patients as startup procedure for closed-loop controlled ventilation. Int J Clin Monit Comput. 1994;11:19-30.

\section{Table 1}

Table 1 Characteristics of the studies included in the meta-analysis 


\begin{tabular}{|c|c|c|c|c|c|c|c|c|c|c|}
\hline study & design & $\begin{array}{l}\text { sample } \\
\text { size }\end{array}$ & age(years) & type of patients & $\begin{array}{l}\mathrm{PaO} 2 / \mathrm{FiO} 2 \text { at } \\
\text { baseline } \\
(\mathrm{mmHg})\end{array}$ & $\begin{array}{l}\text { MV before } \\
\text { randomization } \\
(\mathrm{h}) \\
\end{array}$ & intervention & comparator & ASV initial setting & $\begin{array}{l}\text { primary } \\
\text { outcome }\end{array}$ \\
\hline $\begin{array}{l}\text { Kirakli, } \\
2011\end{array}$ & RCT & 97 & $\begin{array}{l}\text { ASV:64(54-70) } \\
\text { PSV:65(56-70) }\end{array}$ & $\begin{array}{l}\mathrm{COPD}(\mathrm{GOLD}) \\
\left(\mathrm{PaO}_{2} / \mathrm{FIO}_{2} \square 300 \mathrm{mmHg}\right)\end{array}$ & $\begin{array}{l}\text { ASV:182(170- } \\
\text { 198) } \\
\text { PSV:176(168- } \\
184)\end{array}$ & $\square 48 \mathrm{~h}$ & ASV & PSV & $\begin{array}{l}\text { Ppeak } \square 45 \mathrm{cmH} 2 \mathrm{O} \\
\text { VE100mL.kg }{ }^{-1} \text { IBW } \\
\text { PEEP } 3-5 \mathrm{cmH} 20, \\
\text { ETS } \\
40 \%, \mathrm{FiO}_{2} \leq 40 \%\end{array}$ & $\begin{array}{l}\text { Weaning } \\
\text { duration }\end{array}$ \\
\hline $\begin{array}{l}\text { Ritesh, } \\
2013\end{array}$ & RCT & 48 & $\begin{array}{l}\text { ASV:31.4(14.9) } \\
\text { VCV:29.7(11.6) }\end{array}$ & $\begin{array}{l}\text { ARDS } \\
\left(\mathrm{PaO}_{2} / \mathrm{FIO}_{2} \llbracket 200 \mathrm{mmHg}\right)\end{array}$ & $\begin{array}{l}\text { ASV:107.3(41.9) } \\
\text { VCV: } 96.6(34.5)\end{array}$ & $\square 24 \mathrm{~h}$ & ASV & VCV & $\begin{array}{l}\text { Ppeak } \square 45 \mathrm{cmH} 2 \mathrm{O} \\
\text { Pinsp } \square 35 \mathrm{~cm} \\
\text { fR } \square 35 / \mathrm{min} \\
\text { Pplat } \square 35 \mathrm{cmH} 2 \mathrm{O} \\
\text { Vt } 6.6 \mathrm{~mL} / \mathrm{kg} \\
\text { PEEP } 4.9 \mathrm{cmH} 20 \\
\text { SPO } 2 \geq 88 \% \\
\text { FIO2 } \leq .40 \% \\
\text { PH }>7.3\end{array}$ & $\begin{array}{l}\text { duration of } \\
\text { MV } \\
\text { duration of } \\
\text { ICU } \\
\text { stay(days) } \\
\text { hospital } \\
\text { stay } \\
\text { Delta } \\
\text { SOFA } \\
\text { newonset } \\
\text { organ } \\
\text { dysfunction }\end{array}$ \\
\hline Kirakli,2014 & RCT & 229 & $\begin{array}{l}\text { ASV:70(61-79) } \\
\text { P-ACV:73(63- } \\
80)\end{array}$ & $\begin{array}{l}\text { COPD(GOLD) } \\
\text { (PaO2/FIO2₫300mmHg) } \\
\text { Cardiac, } \\
\text { pneumonia, } \\
\text { Cerebrovascular, } \\
\text { Restrictive, } \\
\text { Sepsis, Malignance, } \\
\text { Obesity-hypoventilation }\end{array}$ & 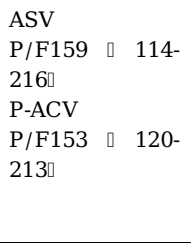 & $\square 24 \mathrm{~h}$ & ASV & P-ACV & $\begin{array}{l}\text { MinVol\% } 100 \% \\
(0.1 / \mathrm{kg} \text { PBW }) \\
\text { PEEP } 3-5 \mathrm{cmH} 20 \text {, } \\
\text { FIO2 } \leq 40 \% \\
\text { ETS }<40 \%\end{array}$ & $\begin{array}{l}\text { the total } \\
\text { MV } \\
\text { duration }\end{array}$ \\
\hline
\end{tabular}

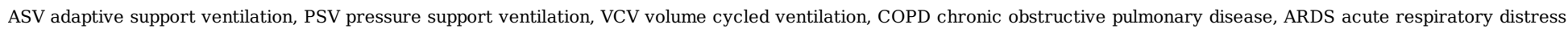

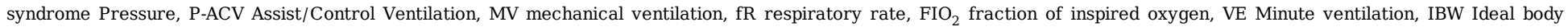

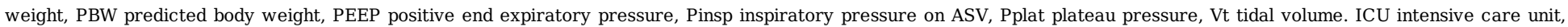
Delta SOFA delta sequential organ failure assessment score, MinVol\% minute ventilation, PBW predicted body weight, ETS expiratory trigger sensitivity

\section{Figures}


Fig 1. Flow Diagram

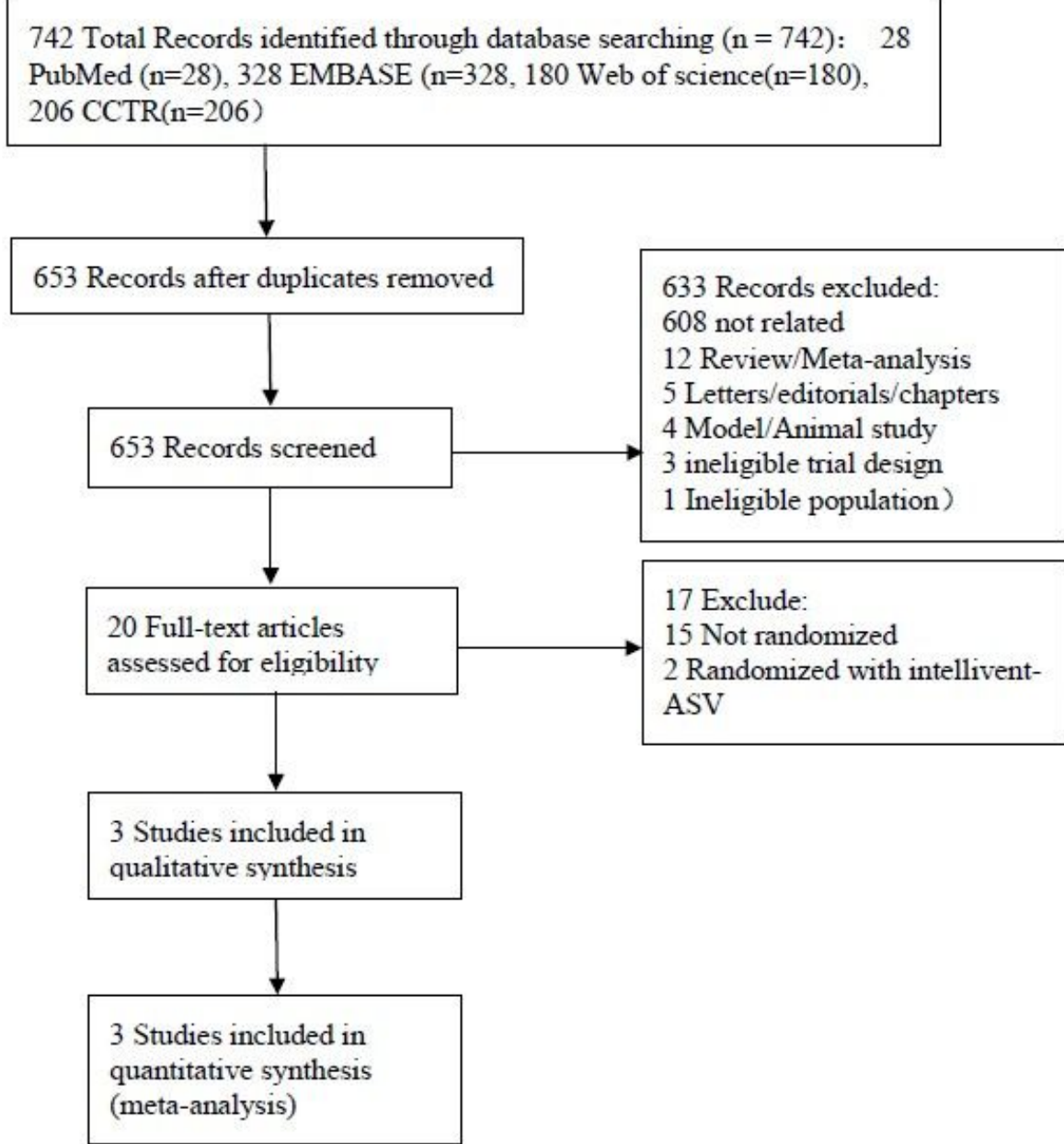

Figure 1

Flow chart 
Fig 2-1: Meta-analysis of randomized controlled trials evaluating effects of ASV on mechanical ventilation by the random-effects model, duration of mechanical ventilation

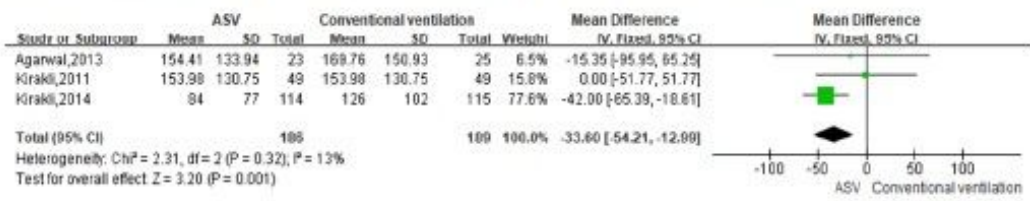

Fig 2-2: Meta-analysis of randomized controlled trials evaluating effects of ASV on ICU length of stay by the random-effects model, ICU length of stay

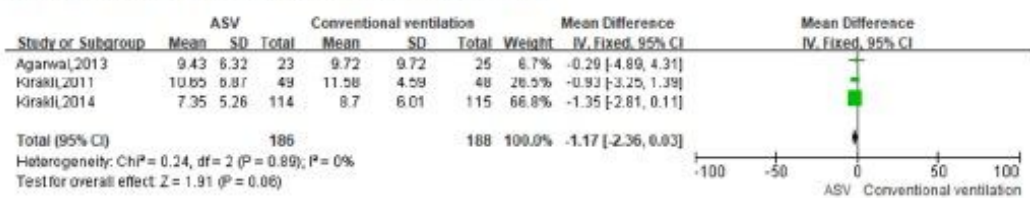

Fig 2-3: Meta-analysis of randomized controlled trials evaluating effects of ASV on weaning duration by the random-effects model, weaning duration

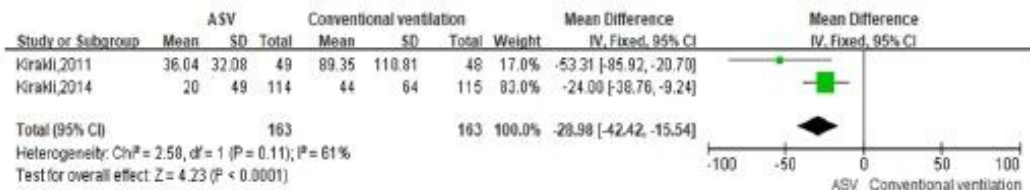

Fig 2-4: Meta-analysis of randomized controlled trials evaluating effects of ASV on weaning success rates by the random-effects model, weaning success rates

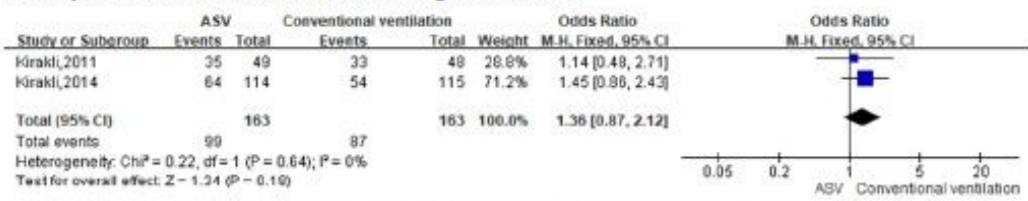

Fig 2-5: Meta-analysis of randomized controlled trials evaluating effects of ASV on 28-day mortality by the random-effects model, weaning success rates, 28 -day mortality.

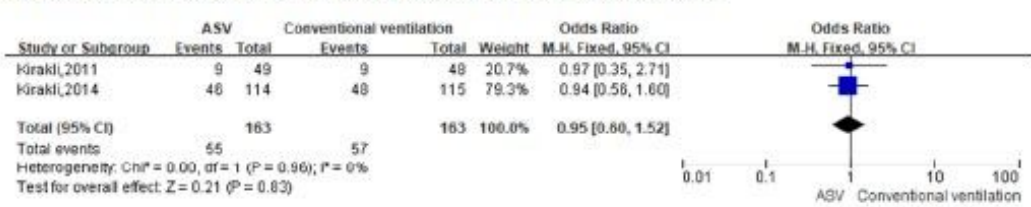

Figure 2

Forest plot 
Fig 3-1: Risk of bias graph: review authors' judgements about each risk of bias item presented as percentages across all included studies

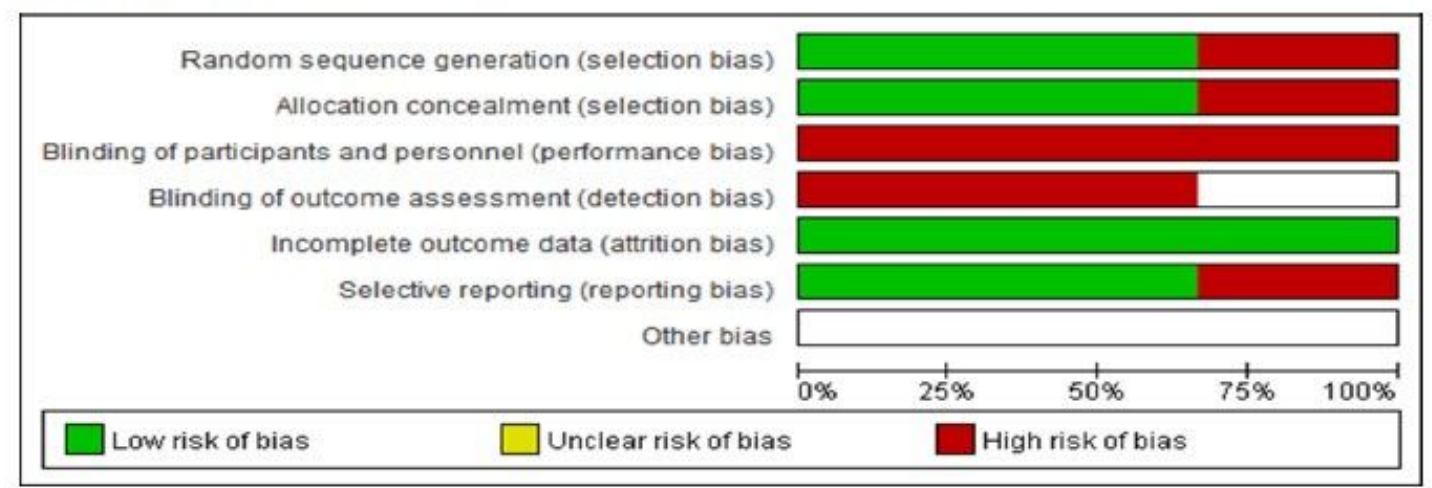

Fig 3-2: Risk of bias summary: review authors' judgements about each risk of bias item for each included study

\begin{tabular}{|c|c|c|c|}
\hline $\begin{array}{l}\text { 즐 } \\
\text { 商 } \\
\frac{0}{0}\end{array}$ & 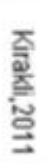 & $\begin{array}{l}\frac{\mathrm{z}}{\mathrm{w}} \\
\frac{\mathrm{w}}{\mathrm{w}} \\
\frac{\mathrm{\sigma}}{\omega}\end{array}$ & \\
\hline & & & Random sequence generation (selection bias) \\
\hline & & & Allocation concealment (selection bias) \\
\hline & & & Blinding of participants and personnel (performance bias) \\
\hline & & & Blinding of outcome assessment (detection bias) \\
\hline & & & Incomplete outcome data (attrition bias) \\
\hline & & & Selective reporting (reporting bias) \\
\hline & & & Other bias \\
\hline
\end{tabular}

Figure 3

Risk of bias graph and bias summary

\section{Supplementary Files}

This is a list of supplementary files associated with this preprint. Click to download.

- icmjecoiform1.pdf 